\title{
COVID-19 pandemic: A challenge for health-care professionals and assessment of anxiety symptoms
}

\author{
Daniel Maestro ${ }^{1,2 *}$, Sabina Šegalo3 ${ }^{3}$ Dinko Remićc,4, Arzija Pašalić2 ${ }^{2}$ Anes Jogunčić5
}

${ }^{1}$ Institute for Public Health of Federation Bosnia and Herzegovina, Sarajevo, Bosnia and Herzegovina, ${ }^{2}$ Faculty of Health Studies, University of Sarajevo, Sarajevo, Bosnia and Herzegovina, ${ }^{3}$ Faculty of Medicine, University of Sarajevo, Sarajevo, Bosnia and Herzegovina, ${ }^{4}$ Public Institution Health Centre of Sarajevo Canton, Sarajevo, Bosnia and Herzegovina, ${ }^{5}$ Institute for Public Health of Canton Sarajevo, Sarajevo, Bosnia and Herzegovina

\begin{abstract}
Introduction: Worldwide, COVID-19 pandemic caused millions of infected people and thousands of deaths. Due to enormous pressure on health-care systems and its inadequate preparedness, utter collapse is expected. In the current epidemic response, healthcare workers' (HCWs) knowledge and practice are crucial, while the impact on their mental health is still unknown.

Methods: The cross-sectional study was conducted among HCWs redeployed to COVID points in the Public Institution Health Centre of Sarajevo Canton. According to guidelines and information provided by the World Health Organization and Ministries of Health, a questionnaire was developed. In addition, General Anxiety Disorder-7 as a screening tool for anxiety disorders was used.
\end{abstract}

Results: Of 180 respondents, 26 (14.4\%) were in direct contact with the sick patient. In total, 79 (43.9\%) respondents consider their personal protective equipment is in accordance with the guidelines of the world health authorities. A total of $72(39.7 \%)$ of respondents used the same mask for several days. In general, the danger from new coronavirus was considered minimal by $59(32,6 \%)$ HCWs. Based on the achieved score for assessing the anxiety disorder, in 63 (35\%) subjects, the presence of severe symptoms was detected.

Conclusion: This study found that most HCWs do not have enough knowledge about the COVID-19 pandemic. We identified that there are differences in the sources of information and gap in perceptions of the native origin of the virus. Considering the frequency of anxiety symptoms among HCWs, interventions are necessary in order to preserve their mental health.

Keywords: COVID-19; health-care professionals; health-care system; anxiety symptoms; practice; attitude and knowledge

\footnotetext{
*Corresponding author: Daniel Maestro, Institute for Public Health of Federation Bosnia and Herzegovina, Sarajevo, Bosnia and Herzegovina, Faculty of Health Studies, University of Sarajevo, Sarajevo, Bosnia and Herzegovina. E-mail: daniel.maestro@fzs. unsa.ba
}

Submitted: 09 September 2020/Accepted: 26 November 2020

\section{INTRODUCTION}

The COVID-19 pandemic is an ongoing global pandemic of coronavirus disease in 2019, caused by SARS-CoV-2 (1). The first case was confirmed in Wuhan City of central Hubei province of China, at the end of 2019 (2). The World Health Organization (WHO) declared the outbreak a public health 
emergency of international concern on 30 January, and a pandemic on 11 March (3). Worldwide, it has caused millions of infected people and thousands of deaths. The first case in Bosnia and Herzegovina was confirmed on the $5^{\text {th }}$ of March. As of May 19, 2020, 2321 cases have been reported and 134 deaths in the country (4).

The lessons learned from previous pandemics are to create enormous pressure on health-care systems, and in case of inadequate preparation, they can lead to their utter collapse. Effective preparedness for pandemic seeks the engagement of the whole health society, and all assets from the health-care system must be ready to meet the increasing demands (5). Therefore, the Government established cantonal crisis headquarters in early February, intending to take measures to protect the population from infectious disease and detect as early as possible cases of COVID-19 (6). In practice, this meant creating an operational plan, reorganization of work, and prepare an effective health system response to a pandemic with a focus on healthcare workers (HCWs) on the front lines as every country's most valuable resource.

For Bosnia and Herzegovina as a developing country, except for the lack of funds for the procurement of personal protective equipment (PPE) (7), an additional problem was its unavailability on the world market. Statements by the Leaders of the WHO that "some of the strongest health systems in the world have been surprised by the pandemic" (7) and first reports from China and Italy with numbers of infected and deceased HCWs (8) have contributed to heightened concerns. In epidemic response, HCWs must have up-to-date knowledge regarding the source, transmission, symptoms, and preventive measures to protect themselves and prevent intra-hospital transmission of infection (9) and all these segments directly increase the risk of infection (10). Studies have shown that HCWs have a higher risk of mental health problems such as anxiety, depression, insomnia, and stress $(11,12)$ due to excessive workload, inadequate PPE, excessive media attention, and feeling of insufficient and inadequately supported (13). Therefore, the aim of this study is to assess the knowledge, attitude, and practice concerning COVID-19 and, additionally, the presence of anxiety disorder symptoms among HCWs in primary care.

\section{METHODS}

\section{Study design and data collection}

The cross-sectional study was conducted from $5^{\text {th }}$ to $19^{\text {th }}$ of May, 2020. Our study participants included HCWs in the Public Institution Health Centre of Sarajevo Canton, redeployed to COVID points (CPs). The main purpose of establishing CPs during the second part of April was patient triage and sampling for mass testing of citizens to combat the infection. The institution did not interrupt the regular work in primary health care. Due to the lack of staff and the fragmentation of the ambulance, the HCWs from all services were reassigned to the CPs. In all six points, the team leaders were doctors, following the instructions of the Cantonal Administration for Inspection Affairs.

Due to the specificity of the virus transmission pathways and to avoid outbreaking, an anonymous self-administered questionnaire was distributed online through the Google form. The confidentiality of personal data was maintained throughout the study by making participants' data anonymous and asking participants to provide reliable answers. Participation in this study was voluntary and was uncompensated. The Ethics Committee of the Institution has given ethical approval to conduct this study. For this research, a questionnaire was developed and divided into four parts. The first part included demographic data of the participants (sex, age, education level, occupation, and work experience). The second part evaluated the knowledge, attitude, and practice of participants with COVID19 (23 questions). A base for the questions was information and recommendations provided by the WHO and ministries of health. For the knowledge section, a score of 5-6 (>83\% of correct answers) provided the basis for the assessment of knowledge as good. In the third part, participants were invited to assess the response of the health system to the pandemic (six questions) and to rate their stress levels on a scale of 1-5. The fourth part is a questionnaire, General Anxiety Disorder-7, taken as a screening tool for symptom severity measures for the four most common anxiety disorders. Calculated score 5-9 indicates mild, 10-14 moderate, and $>15$ presences of severe symptoms. All obtained data were encoded and analyzed using SPSS version 26 (IBM) 
and MS Office 2019. Descriptive analysis was applied to calculate frequencies and proportions. The Chi-square test was used to investigate the level of association between categorical variables. $p<0.05$ was considered statistically significant. For numerical analyses, we used mean value with standard deviation or median with the interquartile range. To test differences between two groups in points about knowledge, we have used the Mann-Whitney U test and Kruskal-Wallis test for three or more groups.

\section{RESULTS}

\section{Demographic characteristics}

Of the 180 respondents, 133 (73.9\%) were females and $47(26.1 \%)$ males. The mean age of individuals was $43.81 \pm 9.46$. Concerning the education level, $104(57.8 \%)$ participants had a high school diploma, $8(4.4 \%)$ higher education, and 68 $(37.8 \%)$ university degrees. Most responders were nurses 77 (42.8\%), followed by doctors $36(20 \%)$, and the rest were other profiles of HCWs. The average length of service was $19.18 \pm 9.24$. Most responders, 77 (42.8\%), had between 11 and 20 years' work experience.

\section{Practice, attitude, and knowledge level of participants}

Of 180 respondents, 26 (14.4\%) were in direct contact with the sick patient. Among them, 37.50\% possess a university degree, and the most frequent contact was made by HCWs with more than 30 years of work experience. For 62 (34.4\%) HCWs, laboratory testing was performed as part of the screening and all samples were negative. The highest number of tested respondents was with higher education, 111 of them $(62.5 \%)$ and 82 employees in the group up to 5 years of service $(46.1 \%)$. Twice less tested respondents, 59 (32.7\%) possessed a high school diploma. Among family members of HCWs, $2(1.1 \%)$ cases of COVID-19 were registered. For $21(11.7 \%) \mathrm{HCW}$, a measure of self-isolation was prescribed by the Crisis Staff of the institution. Most of them, in total 4, had more than 30 years of working experience (18.2\%) and 7 with higher education $(25 \%)$.

In total, 79 (43.9\%) respondents divide the opinion that they have PPE at their workplace in accordance with the guidelines of the world health authorities and $58(32.2 \%)$ assess the available quantities as sufficient. Forty-seven (69.1\%) respondents with a university degree and in the group with 21-30 years of work experience obtained the contrary opinion on the quantities.

During the pandemic, 124 (69.1\%) of exposed HCWs rated their contribution as maximal. Among them, 120 (97\%) believe they did not have omissions in their routine work with patients and that they followed the prescribed procedures. Due to possible contact with the patient, 79 (42.6\%) of respondents share the opinion that their family members and friends avoided contact and 95 $(51.4 \%)$ of them believe that due to the nature of the work they do, they endanger themselves daily. To protect family members, 28 (19.1\%) of respondents resided at another place of residence.

A total of 79 (45.6\%) of respondents used one surgical mask during the working day and 72 (39.7\%) used the same mask for several days. After $2 \mathrm{~h}$, the protective mask was amended by 10 (8.8\%) of respondents, while a periodic change every $4 \mathrm{~h}$ is practiced by 19 (5.9\%) HCWs. The appropriate training on the use and disposal of PPE in the institution received $82(47.1 \%)$ of HCWs.

The primary sources for reliable information about COVID-19 were the Ministry of Health, for 57 $(31.7 \%) \mathrm{HCW}$, this was the primary source, 52 (28.9\%) respondents get the information at the health facility where they work and 15 (27.2\%) in local media. World health authorities were the source for 11 (20.5\%) responders and mostly, $13(27.7 \%)$ of them, with high education, while $19(10.6 \%)$ reported they obtained information about COVID-19 from other sources. A total of 25 (13.9\%) respondents possess adequate knowledge of COVID-19 (score 5-6). Statistical significance was confirmed concerning the length of service $(p=0.0425)$. Summary data are presented in Table 1.

A total of $47(26.1 \%)$ responders knew the time interval when fever occurs as a symptom, and the most accurate answers were provided by HCWs with secondary education $(27.9 \%)$. The initial symptoms of the disease (dry cough, fever, and fatigue) were correctly marked by 88 (48.9\%) 
subjects and the length of the average incubation period by 80 (44.4\%). A total of $122(67.8 \%)$ HCWs knew the exact definition of a confirmed case. Among HCWs, 14 (7.8\%) of them believe that $70 \%$ of ethanol is not the most effective hand sanitizer. The native origin of the virus was indicated by 78 (42.2\%), and among them, the majority possessed a secondary education (49.1\%). A total of 19 $(10.6 \%)$ connects the pandemic to the $5 \mathrm{G}$ network, $88(48.9 \%)$ share the view on the laboratory origin of the virus, most respondents with higher and university degrees. Statistical significance for this set of questions concerning gender, length of service, and level of education has been unconfirmed (Table 2).

\section{Perceptions about the health-care system in COVID-19 pandemic}

Table 3 presented the views of HCWs on the health facility's readiness to respond to the COVID-19 pandemic, the measures and expertise of the relevant crisis staff, the availability of PPE, and the institutions' care for their mental health. In relation to the level of education and length of service, no statistically significant difference was recorded in the answers $(p>0.05)$. In general, the new coronavirus was considered to be moderately dangerous by 74 (41.2\%) HCWs. For 24 (13.2\%), it is significant, while $59(32.6 \%)$ stated that the danger is minimal. Perceptions about the health-care system in the COVID-19 pandemic are presented in Table 3.

\section{Anxiety symptoms among healthcare workers}

Based on the achieved score for assessing the anxiety disorder, in $63(35 \%)$ subjects, the presence of severe symptoms was detected (score > 15), 22 (12.2\%) were with mild (score 5-9) and 15 (8.3\%) with moderate, while 80 (44.4\%) were asymptomatic. Results of the assessment of the presence of

TABLE 1. Achieved score for the segment of knowledge in relation to gender, education, and length of service

\begin{tabular}{|c|c|c|c|c|}
\hline \multicolumn{5}{|c|}{ Gender (N/\%) } \\
\hline Scores & Male & Female & $x^{2}$ & $p$ \\
\hline $1-4$ & $42 / 89.4$ & $113 / 85.0$ & 0.254 & 0.614 \\
\hline $5-6$ & $5 / 10.6$ & $20 / 15.0$ & & \\
\hline
\end{tabular}

\begin{tabular}{|c|c|c|c|c|c|c|c|}
\hline \multicolumn{8}{|c|}{ Educational level (N/\%) } \\
\hline Scores & High school education & \multicolumn{3}{|c|}{ Higher school education } & University education & $x^{2}$ & $p$ \\
\hline $1-4$ & $89 / 85.6$ & \multicolumn{3}{|c|}{$8 / 100$} & $58 / 85.3$ & 1.353 & 0.508 \\
\hline $5-6$ & $15 / 14.4$ & \multicolumn{3}{|c|}{$0 / 0$} & $10 / 14.7$ & & \\
\hline \multicolumn{8}{|c|}{ Length of service in years (N/\%) } \\
\hline Scores & $0-5$ & $6-10$ & $11-20$ & $21-30$ & $30+$ & $x^{2}$ & $p$ \\
\hline $1-4$ & $8 / 61.5$ & $11 / 91.7$ & $71 / 92.2$ & $40 / 85.1$ & $18 / 81.8$ & 9.88 & 0.0425 \\
\hline $5-6$ & $5 / 38.5$ & $1 / 8.3$ & $6 / 7.8$ & $7 / 14.9$ & $4 / 18.2$ & & \\
\hline
\end{tabular}

TABLE 2. Knowledge of health workers compared to gender, length of service, and educational level

\begin{tabular}{lccccccc}
\hline & & Mean & Median & Perc. 25 & Perc. 75 & Mann-Whitney U test & $p$ \\
\hline Gender & Male & 3.13 & 3.00 & 2.00 & 4.00 & 3.125 & 0.99 \\
& Female & 3.19 & 3.00 & 2.00 & 4.00 & & \\
\hline Length of service & & Mean & Median & Perc. 25 & Perc. 75 & Kruskal-Wallis test & $p$ \\
& $0-5$ & 3.85 & 4.00 & 2.00 & 5.00 & 2.178 & 0.703 \\
& $6-10$ & 3.08 & 3.00 & 2.50 & 4.00 & & \\
& $11-20$ & 3.12 & 3.00 & 2.00 & 4.00 & & \\
\multirow{5}{*}{ Educational level } & $21-30$ & 3.17 & 3.00 & 2.00 & 4.00 & & \\
& $30+$ & 3.18 & 3.00 & 2.00 & 4.00 & & \\
& High school & 3.25 & 3.00 & 2.00 & 4.00 & & \\
& Higher school & 2.75 & 2.00 & 2.00 & 4.00 & & \\
& University & 3.10 & 3.00 & 2.00 & 4.00 & & \\
\hline
\end{tabular}


TABLE 3. Perceptions about health-care system in COVID-19 pandemic (by educational level)

\begin{tabular}{|c|c|c|c|c|c|c|}
\hline \multirow[t]{2}{*}{ Questionnaire } & \multicolumn{6}{|c|}{ Descriptive statistics } \\
\hline & Mean & Std. deviation & Minimum & Maximum & Kruskal-Wallis & $p$ \\
\hline $\begin{array}{l}\text { Assess the state of the health system in Sarajevo } \\
\text { Canton? }\end{array}$ & 2.94 & 1.265 & 1 & 5 & 2.955 & 0.228 \\
\hline $\begin{array}{l}\text { Granting to your opinion, how readily did your institution } \\
\text { respond to the current pandemic? }\end{array}$ & 3.50 & 1.143 & 1 & 5 & 0.291 & 0.864 \\
\hline $\begin{array}{l}\text { Do you believe in the expertise and measures of the } \\
\text { competent crisis headquarters in the fight against the } \\
\text { pandemic? }\end{array}$ & 3.11 & 2.695 & 1 & 35 & 2.588 & 0.274 \\
\hline $\begin{array}{l}\text { Does taken hygienic-epidemiological measures to } \\
\text { represent a key factor in the control of the epidemic in } \\
\text { the country? }\end{array}$ & 3.51 & 1.161 & 1 & 5 & 1.721 & 0.423 \\
\hline $\begin{array}{l}\text { Is PPE available in your institution in accordance with the } \\
\text { recommendations of the world health authorities? }\end{array}$ & 3.05 & 1.240 & 1 & 5 & 0.036 & 0.982 \\
\hline Evaluate your stress level during the current pandemic? & 3.60 & 1.428 & 1 & 5 & 2.306 & 0.316 \\
\hline $\begin{array}{l}\text { Evaluate the care of the competent institutions about } \\
\text { the mental health of healthcare workers during the } \\
\text { pandemic? }\end{array}$ & 1.87 & 1.166 & 1 & 5 & 2.813 & 0.245 \\
\hline
\end{tabular}

anxiety disorder symptoms compared to the length of service are shown in Figure 1. In 29 (37.5\%) respondents who felt nervous, anxious, or "on the edge" were HCWs with higher education and 24 $(33.3 \%)$ of them with a length of service of $11-20$ years. In the same group, 25 (37.5\%) of respondents stated that they felt uncontrolled concern every day. HCWs with a higher and university education have the most problems with relaxation after work, and $26(64.4 \%)$ of them stated these problems are continuous. Symptoms of everyday fatigue declared $71(39.4 \%)$ and increased irritability 76 (36.6\%) HCWs. These symptoms were primarily found among employees with higher education. Every day bad feelings were expressed by 30 HCWs (28.8\%) with secondary education, $3(37.5 \%)$ with higher education, and $9(13.2 \%)$ with high education $(p<0.05)$. The Kruskal-Wallis test - grouping variable by educational level are presented in Table 4 .

\section{DISCUSSION}

The COVID-19 pandemic is the cause of significant changes in the living habits of the population and the organization of the work of health-care institutions. As a small resource-constrained country, Bosnia and Herzegovina has had to face the great challenge of preparing a response to a pandemic. The current situation was further complicated by

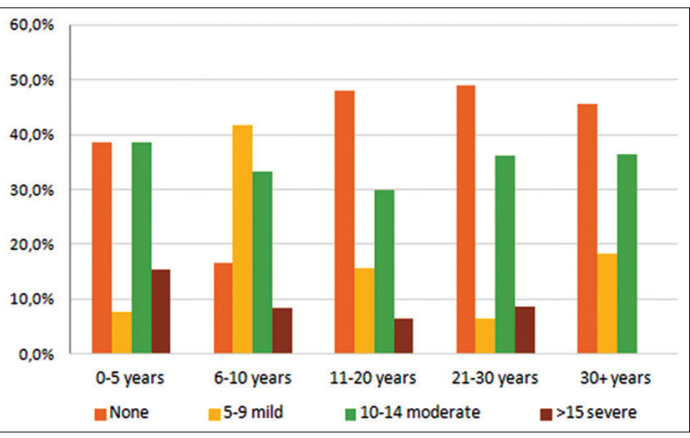

FIGURE 1. Assessment of the presence of anxiety disorder symptoms compared to the length of service.

insufficient information about the virus itself. The hygienic-epidemiological measures taken by the Crisis Headquarters have been marked as radical in most media and among the population, but statistics show that they have proved successful compared to highly developed countries where the virus has spread uncontrollably. In the global crisis, the biggest burden was carried by HCWs, so our goal was to examine their knowledge and perceptions of the prevention and control of COVID-19 and the impact of the pandemic on their mental health.

In this study, most of the participants were females (73.9\%), which are correlated with similar studies by Nemati et al. and Lai et al. $(9,12)$, and deviates from the results of studies conducted in various 
TABLE 4. Kruskal-Wallis test - grouping variable by educational level

\begin{tabular}{lccc}
\hline Question & Kruskal-Wallis Test & df & Asymptomatic signs \\
\hline Feeling nervous, anxious, or on edge? & 3.014 & 3.014 & 3.014 \\
Not being able to stop or control worrying? & 3.469 & 3.469 & 3.469 \\
Worrying too much about different things? & 0.763 & 0.763 & 0.763 \\
Trouble relaxing? & 3.227 & 3.227 & 3.227 \\
Being so restless that it is hard to sit still? & 3.133 & 3.133 & 3.133 \\
Becoming easily annoyed or irritable? & 0.858 & 0.858 & 0.858 \\
Feeling afraid as if something awful might happen? & 8.824 & 8.824 & 8.824 \\
\hline
\end{tabular}

geographical areas $(10,14,15)$, with which these differences can be related. Our respondents were dominated by nurses/technicians (42.8\%) and other profiles with secondary education (57.8\%). Our results are in accordance with studies conducted in China and Iran $(9,10)$ and deviate from the results of studies by Bhagavathula et al. and Olum et al. in which physicians $(14,15)$ most often participated. Significant discrepancies are observed in the level of education of our respondents, compared to a study conducted in Uganda, where $92 \%$ possessed at least a bachelor's degree (15).

In our study, the majority of the HCWs (86.1\%) had insufficient knowledge about COVID-19, and a better overall score was achieved by respondents with secondary education and in the group up to 5 years of work experience. Our results are in accordance with the study of Bhagavathula et al., which included respondents from all continents (14). They significantly deviate from studies with a good level of knowledge (69-90\%) regardless of geographical area and targeted population $(9,15-19)$.

The analysis of specific questions for knowledge evaluation did not determine statistical significance with gender, length of service, and level of education, which is contrary to the studies of Zhang et al. and Bhagavathula et al. In these studies, doctors demonstrated better knowledge about the incubation period and initial symptoms compared to other profiles of HCWs $(10,14)$. In addition, $59.5 \%$ of HCWs support conspiracy theories about the association of the virus with the $5 \mathrm{G}$ network and possible biosecurity failures in the Wuhan laboratory. Our results are contradicting the research of Bhagavathula et al. and Taghrir et al. $(14,19)$. Reasonable explanations for these results are hard to provide. One of the possibilities is that due to the reorganization of work, HCWs of profiles were transferred to the $\mathrm{CP}$, which for the $1^{\text {st }}$ time encountered changed working conditions during the pandemic and performed this type of work. Moreover, the hygienic-epidemiological measures implemented in the country significantly reduced the spread of the virus in the community, so starting from the assumption that the scenario that befell Italy would be avoided in the country, they believed that at that time they had detailed knowledge of COVID 19 protection is unrequired. This is supported by the fact that COVID centers have been established in clinical center and hospitals, where the most competent staff with long-term clinical experience has been redeployed and they have successfully borne the brunt of the current pandemic. Another concern is slight differences $(\approx 3 \%)$ in the use of scientific and authentic content and local media as a source of information on emerging disease. Our findings are not in accordance with the results of Olum et al., where the primary sources of information were international health organizations such as the Centers for Disease Control and Prevention and WHO 119 (88\%) and the Ministry of Health 107 (79\%) (15). This indicates that the COVID-19 related updates posted online by official Bosnian government health authorities did not have positive and expected implications for improving HCWs' knowledge compared to strong media influence. Even the official media provided synchronous support to the health sector and the Government, access to pseudoscientific news through the Internet resulted in the rapid spread of malicious information about conspiracy theories. Sad to relate, HCWs did not stay immune either. Studies conducted by Olum et al. pointed to the impact of media on knowledge and their importance on the dissemination of 
authentic information regarding COVID-19 (15). From this pandemic, we have learned education on the importance of using scientific and authentic sources to collect data on emergent pathogens is crucial. Our respondents assessed the response of the institution and the Government to the current pandemic as satisfactory, which is contrary to the study conducted in Egypt and Nigeria (20). In this study, half of the respondents $(51.4 \%)$ think that due to the nature of the work they perform to endanger family members, which is significantly $<75.2 \%$ and $92 \%$ in the studies by Wang et al. and Ahmed et al. $(21,22)$. In total, $94(52.2 \%)$ respondents were instructed on the proper use and disposal of protective equipment. Most of them possess a university degree $(47.1 \%)$ and belong in a group with 6-10 years of work experience. Our results correlate with the study by Zhang et al., which found that careful removal of protective equipment was positively associated with a higher education level (10). On average, $32.6 \%$ of respondents believe that the risk of the new coronavirus is minimal, which is in contrast to a study conducted in Italy where 60\% of responders are quite enough or a lot worried (16).

Previous research on SARS and Ebola indicates the severity of emotional distress during such epidemics (23). In our study, of the 180 HCWs, 78 (43.3\%) screened positive for moderate to extremely severe anxiety symptoms. Our results are in line with the study conducted among dentists, who, despite maintaining a high level of knowledge and practice, are in a condition of anxiety and fear (22). Furthermore, our findings are consistent with the results Lai et al. conducted among HCWs in Wuhan, where anxiety symptoms were reported by $560(44.6 \%)$ responders (12). A rare frequency of moderate to severe anxiety symptoms $(28.8 \%)$ was presented in a study by Chew et al. using depression, anxiety, and stress scale-21 as a screening tool (24). Our results suggest that competent institutions should focus on the mental health of HCWs and analyze in detail the causes of anxiety and self-assessed levels of stress. Interventions in this domain are demanded due to the expressed dissatisfaction of respondents with the measures taken on mental health, and future events and the possible arrival of a second wave when all HCWs might be needed are unpredictable.

\section{CONCLUSION}

Our study found that most health workers have insufficient knowledge about the COVID-19 pandemic. We identified that there are differences in the sources of information and gap in perceptions of the native origin of the virus. Therefore, efforts through educational campaigns on the importance of using scientific and authentic sources to collect data on emerging pathogens are urgently needed. The research confirmed the power of media information; therefore, Government bodies should intensify the use of this tool to provide adequate and scientifically-based information to the general and target population. Considering the frequency of anxiety symptoms among healthcare workers, interventions by competent institutions are necessary to preserve their mental health.

\section{ACKNOWLEDGMENTS}

We thank all healthcare workers for their participation in the survey and for providing needed information.

\section{Limitations}

This study is a cross-sectional study conducted online among HCWs and the data presented are self-reported and partly dependent on the participants' honesty.

\section{REFERENCES}

1. World Health Organization. Naming the Coronavirus Disease (COVID-19) and the Virus That Causes it. Geneva: World Health Organization; 2020. Available from: https://www.who.int/emergencies/diseases/novel-coronavirus-2019/technical-guidance/naming-the-coronavirus-disease-(covid2019)-and-the-virus-that-causes-it. [Last accessed on 2020 May 19].

https://doi.org/10.4060/cb0180en.

2. Holshue M, DeBolt $\mathrm{C}$, Lindquist S, Lofy K, Wiesman J, Bruce $\mathrm{H}$, et al First case of 2019 novel coronavirus in the United States. N Engl J Med 2020;382(10):929-36.

https://doi.org/10.1056/nejmoa2001191.

3. World Health Organization. WHO Director-general's Opening Remarks at the Media Briefing on COVID-19. Geneva: World Health Organization; 2020. Available from: https://www.who.int/dg/speeches/detail/who-director-general-s-opening-remarks-at-the-media-briefing-on-covid-19---11march-2020. [Last accessed on 2020 May 19].

https://doi.org/10.1093/ww/9780199540884.013.u161119.

4. Worldometer. Coronavirus Update (Live): 4,917,473 Cases and 320,609 Deaths from COVID-19 Virus Pandemic-Worldometer; 2020. Available from: https://www.worldometers.info/coronavirus. [Last accessed on 2020 May 19].

5. Centres for Disease Control and Prevention. Healthcare System 
Preparedness and Response Pandemic Influenza (Flu), CDC; 2016. Available from: https://www.cdc.gov/flu/pandemic-resources/planning-preparedness/healthcare-preparedness-response.html. [Last accessed on 2020 May 19].

https://doi.org/10.1201/9781420060881.ch2.

6. Crisis Headquarters of the Federal Ministry of Health. Order of the Crisis Headquarters of the Federal Ministry of Health; 2020. Available from: http:// www.fbihvlada.gov.ba/01_Naredba\%20KS\%20FMZ\%203.2.2020.pdf. [Last accessed on 2020 May 19].

7. World Health Organization. How to Protect Health Workers Now: WHO COVID-19 Briefing. World Economic Forum; 2020. Available from: https:// www.weforum.org/agenda/2020/04/10-april-who-briefing-health-workerscovid-19-ppe-training. [Last accessed on 2020 May 19] https://doi.org/10.31219/osf.io/thdwm.

8. The Lancet. COVID-19: Protecting health-care workers. Lancet 2020;395:922

https://doi.org/10.1016/s0140-6736(20)30644-9

9. Nemati M, Ebrahimi B, Nemati F. Assessment of Iranian nurses' knowledge and anxiety toward COVID-19 during the current outbreak in Iran. Arch Clin Infect Dis 2020;15:e102848.

https://doi.org/10.5812/archcid.102848.

10. Zhang M, Zhou M, Tang F, Wang Y, Nie H, Zhang L, et al. Knowledge, attitude, and practice regarding COVID-19 among healthcare workers in Henan, China. J Hosp Infect 2020;105(2):183-7.

https://doi.org/10.1016/j.jhin.2020.04.012.

11. Liu S, Yang L, Zhang C, Xiang Y, Liu Z, Hu S, et al. Online mental health services in China during the COVID-19 outbreak. Lancet Psychiatry 2020;7(4):e17-8. https://doi.org/10.1016/s2215-0366(20)30077-8.

12. Lai J, Ma S, Wang Y, Cai Z, Hu J, Wei N, et al. Factors associated with mental health outcomes among health care workers exposed to coronavirus disease 2019. JAMA Netw Open 2020;3(3):e203976. https://doi.org/10.1001/jamanetworkopen.2020.3976.

13. Spoorthy M, Pratapa S, Mahant S. Mental health problems faced by healthcare workers due to the COVID-19 pandemic-a review. Asian J Psychiatr 2020;51:102119. https://doi.org/10.1016/j.ajp.2020.102119.

14. Bhagavathula A, Aldhaleei W, Rahmani J, Mahabadi M, Bandari D. Knowledge and perceptions of COVID-19 among health care workers: Cross-sectional study. JMIR Public Health Surveill 2020;6(2):e19160. https://doi.org/10.2196/preprints.19160.
15. Olum R, Chekwech G, Wekha G, Nassozi D, Bongomin F. Coronavirus disease-2019: Knowledge, attitude, and practices of health care workers at makerere university teaching hospitals, Uganda. Front Public Health 2020;8:181.

https://doi.org/10.3389/fpubh.2020.00181.

16. Moro M, Vigezzi G, Capraro M, Biancardi A, Nizzero P, Signorelli C, et al. 2019-novel coronavirus survey: Knowledge and attitudes of hospital staff of a large Italian teaching hospital. Acta Biomed 2020;91(3-S):29-34. https://doi.org/10.1093/eurpub/ckaa166.608.

17. Clements JM. Knowledge and behaviours toward COVID-19 among US residents during the early days of the pandemic. MedRxiv 2020;6(2):e19161. https://doi.org/10.2196/preprints.19161.

18. Giao H, Han NT, Van Khanh T, Ngan VK, Van Tam V, Le An P. Knowledge and attitude toward COVID-19 among healthcare workers at district 2 hospital, Ho Chi Minh city. Asian Pacific J Trop Med 2020;13(6):260-5.

19. Taghrir M, Borazjani R, Shiraly R. COVID-19 and Iranian medical students; a survey on their related-knowledge, preventive behaviors and risk perception. Arch Iran Med 2020;23(4):249-54

https://doi.org/10.34172/aim.2020.06.

20. Elnadi H, Odetokun I, Bolarinwa O, Ahmed Z, Okechukwu O, Al-MustaphaA. Knowledge, attitude, and perceptions towards the 2019 coronavirus pandemic: A bi-national survey in Africa. PLoS One 2020;15(7):e0236918. https://doi.org/10.1101/2020.05.27.20113951

21. Wang C, Pan R, Wan X, Tan Y, Xu L, Ho C, et al. Immediate psychological responses and associated factors during the initial stage of the 2019 coronavirus disease (COVID-19) epidemic among the general population in China. Int J Env Res Public Health 2020;17(5):1729. https://doi.org/10.3390/ijerph17051729.

22. Ahmed M, Jouhar R, Ahmed N, Adnan S, Aftab M, Zafar M, et al. Fear and practice modifications among dentists to combat novel coronavirus disease (COVID-19) outbreak. Int J Environ Res Public Health 2020;17(8):2821. https://doi.org/10.3390/ijerph17082821.

23. Lee SM, Kang WS, Cho AR, Kim T, Park JK. Psychological impact of the 2015 MERS outbreak on hospital workers and quarantined hemodialysis patients. Compr Psychiatry. 2018;87:123-7. https://doi.org/10.1016/j.comppsych.2018.10.003.

24. Chew N, Lee G, Tan B, Jing M, Goh Y, Ngiam N, et al. A multinational, multicentre study on the psychological outcomes and associated physical symptoms amongst healthcare workers during COVID-19 outbreak. Brain Behav Immun 2020;88:559-65.

https://doi.org/10.1016/j.bbi.2020.04.049. 